\title{
Research Progress of the Structure Vibration-Attitude Coordinated Control of Spacecraft
}

\section{Jingyu Yang*, Shiying Qu , Jiahui Lin , Zhiqi Liu , Xuanming Cui , Chu Wang , Dujiang Zhang , Mingcheng gu , Zhongrui Sun and Kang Yang}

Laboratory of Space Solar Power Station Dynamics and Control, Faculty of Aerospace Engineering, Shenyang Aerospace University, Shenyang 110136, China

\section{Lanwei Zhou and Guoping Chen}

The State Key Laboratory of Mechanics and Control for Mechanical Structures, Nanjing University of Aeronautics and Astronautics, Nanjing 210016, China

\begin{abstract}
This paper gives an overview of research on the field of structure vibration-attitude coordinated control of spacecraft. First of all, the importance of the technology has been given an introduction, and then later the research progress of space structure dynamics modeling, research progress of structure vibration-attitude coordinated control of flexible spacecraft have been discussed respectively. Finally, future research on application of structure vibration-attitude coordinated control of spacecraft has been recommended.
\end{abstract}

Key words: spacecraft, vibration-attitude coordinated control, overview

\section{Introduction}

The first earth orbiting satellite Sputnik was launched by the Soviet Union in 1957. The early spacecraft carried their own source of power to accomplish the desired mission objectives. Typically it was either chemical or electrochemical ${ }^{[1]}$. The missions, mostly scientific, were of relatively short duration and therefore these sources proved to be adequate. The advent of satellites for communication, remote sensing, weather forecasting etc., created the need for a longer lasting supply of power. A logical source was the sun, and as satellite technology matured during the sixties and seventies, satellites were designed with solar arrays for photovoltaic power generation. This coupled with more demanding mission requirements, which were beginning to include meteorology and surveillance, resulted in an increase in the size of satellites. The high cost of delivering payloads to space necessitated that the mass and pre-deployed volume of satellites remain low. These seemingly conflicting demands were satisfied by developing satellites with flexible, light solar arrays and, in some case, antennae which were deployed once the spacecraft had attained their final orientation. Thus, the early artificial satellites could be characterized as being essentially rigid bodies, while current ones are represented by flexible, multi-body systems.

Of course this is a convenient generalization. Even the early, so-called, rigid satellites were often greatly influenced by flexibility effects. An example of this was the first American prove, Explorer I. Stability analysis of a rigid body in the absence of energy dissipation shows that it can be stabilized by imparting spin about either the major or the minor inertia axes. However, in the presence of energy dissipation only the configuration with spin about the major axis of inertia is stable ${ }^{[2]}$. Unfortunately, Explorer I was spun about its minor axis.
This is an Open Access article distributed under the terms of the Creative Commons Attribution Non-Commercial License (http://creativecommons.org/licenses/by$\mathrm{nc} / 3.0 /$ which permits unrestricted non-commercial use, distribution, and reproduction in any medium, provided the original work is properly cited. 
Furthermore, it was equipped with small, flexible antennae which were a source of energy dissipation, rendering its librational behaviour unstable. Within ninety minutes of orbit injection it was tumbling to the dismay of engineers at the Jet Propulsion Laboratory (JPL) ${ }^{[3]}$. The flexible character of modern spacecraft is much more pronounced as illustrated by a few examples of contemporary interest:

The Japanese Space Flyer Unit (SFU), an unmanned, reusable, free-flying platform for multipurpose use, is scheduled for launch by the H-II rocket in 1995. It consists of an octogonally shaped central body of about $5 \mathrm{~m}$ in width, with two solar arrays each approximately $10 \mathrm{~m}$ in width, with two solar arrays each approximately $10 \mathrm{~m}$ in length.

The European Space Agency's (ESA) L-SAT (Large Satellite system, Olympus-I) was launched in 1989. It is an advanced multipurpose communications platform with two solar arrays extending to $25 \mathrm{~m}$, tip-to-tip. A follow-up to Olympus-I is proposed with solar panels that extending beyond $35 \mathrm{~m}$.

The Earth Observing System (EOS) is aimed at remote sensing of global environmental changes. Comprising of a system of around 50-90 satellites in Low Earth Orbit (LEO), it is aimed at monitoring phenomena such as global warming, carbon dioxide and methane concentrations, loss of vegetation, etc. A typical EOS spacecraft has an asymmetric geometry, with as single solar panel extending from the satellite's main body.

The proposed Space Station, a permanently manned platform being developed collaboratively by the United States, ESA, Japan, Canada and the recently added partner Russia. The principle objective of the program is the utilization of space for scientific research and technology development. The proposed space station has undergone numerous configurational changes since its inception, and will likely undergo more modification before it becomes a reality by the turn of the century. The current design of the station consists of a $110 \mathrm{~m}$ long central truss-like structure called the Power Boom. Attached to both ends of the Boom are plate-like solar arrays, each extending to $33 \mathrm{~m}$.

Challenges in the area of spacecraft control in clued simultaneous libration and vibration and shape control, presence of large mechanical flexibilities and require of stringent vibration suppression and pointing accuracies. Balas ${ }^{[4]}$ has highlighted the characteristics of space structures as

I distributed parameter systems, consequently infinite dimensional in theory, and very large dimensional in practice.

II systems with many closely spaced low resonant frequencies.

III systems with poorly known natural damping $(\approx 0.5$ percent critical) and very light.

IV systems whose behavioral prediction in space via onearth testing is quite limited.

V systems whose requirements for shape, orientation, alignment, vibration suppression, and pointing accuracy are very stringent.

Spacecraft experience of the past five decades (see Table 1) indicates that control/structure interaction effects must be included in the design process, even for the traditional spacecraft configurations. Most importantly the advent of the Space Transportation System (STS) has sparked the conception of advanced space system configurations for which structural flexibility is not merely a matter of marginal impact but actually dominates projected system performance. It was recognized in the late 1970s that the highly flexible advanced space system concepts involving many sensors and effectors require the development of correspondingly advanced multi-input, multi-output (MIMO) control design techniques. Over the ensuing decade, the technical challenges of this development have stimulated the emergence of a distinct technological field which may be termed "Structure Vibration and Coordinated Attitude Control of Spacecraft".

\section{Research Progress Of Space Structure Dy- namics Modeling}

In the 70's of last century, the famous American scientists called Likins who engaged in the study of spacecraft dynamics has done a lot of research on the flexible system dynamics modeling. In the late 1970s, many foreign scholars thought the future development trend of large spacecraft is beginning to the theoretical research of large space structure dynamics modeling, particularly studying the large space platform, large manned space station and space base, etc. After 80's of last century, with the rapid development of computer technology and finite element technology, the study of flexible multi-body system dynamics has been popular, many scholars like Boland, Meirovitch, Hughes, Modi, Huston, Shabana and Kane have made outstanding contributions in researching and development of flexible multi-body spacecraft dynamics modeling. So far, the flexible multi-body system dynamics modeling methods which has obvious advantages are modal synthesis method, Geometric precision method, the absolute nodal coordinate method, the hybrid coordinate method and integrated modeling method.

The core idea of the modal synthesis method is that flexible body described by modal linear superposition in the 
reference coordinate system because the deformation of it is small. Its disadvantage is that the method can only describe the deformation problems but don't suitable for flexible multi-body system dynamics modeling under the conditions of large deformation and large rotation.

Geometric precision method proposed by Professor SIMO, its core idea is to select the rotation vector. There are 3 components regarding as generalized coordinates. But it is

Table 1. Control/structure interaction problems have occurred in every stage of space system life cycles with impact ranging from moderate to very serious

\begin{tabular}{|c|c|c|c|c|}
\hline Year & Satellite & $\begin{array}{l}\text { Control } \\
\text { technique } \\
\end{array}$ & Problem & Probable explanation for problem(s) \\
\hline 1958 & Explorer 1 & $\begin{array}{l}\text { Spin } \\
\text { stabilized }\end{array}$ & Unstable & Energy dissipation in whip antennas \\
\hline 1962 & Mariner & $\begin{array}{l}\text { Attitude } \\
\text { thrusters }\end{array}$ & $\begin{array}{l}\text { Stable, gyros } \\
\text { saturated }\end{array}$ & Solar panel flexibilty changed center of gravity \\
\hline 1962 & Alouette 1 & $\begin{array}{l}\text { Spin } \\
\text { stabilized }\end{array}$ & Rapid spin decay & Solar torque on thermally deformed vehicle \\
\hline 1963 & $1963-22 \mathrm{a}$ & $\begin{array}{l}\text { Gravity } \\
\text { stabilized }\end{array}$ & $\begin{array}{l}\text { Vibrations excessive, } \\
\text { but within } \\
\text { specification }\end{array}$ & Boom bending due to solar heating \\
\hline 1966 & OGO III & $\begin{array}{l}\text { Reaction } \\
\text { wheel }\end{array}$ & $\begin{array}{l}\text { Excessive oscillations } \\
\text { in attitude }\end{array}$ & Control system interaction with flexible booms \\
\hline 1966 & OGO IV & $\begin{array}{l}\text { Gravity } \\
\text { stabilized }\end{array}$ & 1-2-deg oscillation & Solar radiation induced boom bending \\
\hline 1969 & TACSAT 1 & $\begin{array}{l}\text { Spin } \\
\text { stabilized }\end{array}$ & $\begin{array}{l}\text { Limit cycle, but } \\
\text { within specification }\end{array}$ & Energy dissipation in bearing assembly \\
\hline 1969 & ATS V & $\begin{array}{l}\text { Spin } \\
\text { stabilized }\end{array}$ & Unstable & Energy dissipation in heat pipes \\
\hline 1972 & DMSP & $\begin{array}{l}\text { 3-Axis } \\
\text { torque } \\
\text { balance }\end{array}$ & $\begin{array}{l}\text { Solar array and } \\
\text { controller interacted }\end{array}$ & Design was based on rigid body \\
\hline 1973 & Mariner 10 & $\begin{array}{l}\text { Attitude } \\
\text { thrusters }\end{array}$ & $\begin{array}{l}\text { Unstable roll, } \\
\text { depleted fuel }\end{array}$ & $\begin{array}{l}\text { Thrusters and gyros noncollocated with } \\
\text { flexible panels between them }\end{array}$ \\
\hline 1977 & Voyager & $\begin{array}{l}\text { Attitude } \\
\text { thrusters }\end{array}$ & $\begin{array}{l}\text { Flutter of boom } \\
\text { antenna }\end{array}$ & Thermal bending coupled with low torsional stiffness \\
\hline 1978 & $\begin{array}{l}\text { Communications } \\
\text { Technology Satellite } \\
\text { (CTS) }\end{array}$ & $\begin{array}{l}\text { Spin } \\
\text { stabilized }\end{array}$ & Unstable & $\begin{array}{l}\text { Three-axis stabilized satellite experienced "Thermal } \\
\text { elastic shock"during eclipse transitions }\end{array}$ \\
\hline 1980 & LANDSAT 4/5 & $\begin{array}{l}\text { Attitude } \\
\text { thrusters }\end{array}$ & Vibrations excessive & $\begin{array}{l}\text { "Thermal snap"experienced during orbital eclipse } \\
\text { transitions due thermal bending of large single wing } \\
\text { solar array }\end{array}$ \\
\hline 1982 & LANDSAT & $\begin{array}{l}\text { Spin } \\
\text { stabilized }\end{array}$ & 0.1-deg oscillation & $\begin{array}{l}\text { Thermal bending induced by entering and leaving } \\
\text { umbra }\end{array}$ \\
\hline 1984 & LEASAT & $\begin{array}{l}\text { Spin } \\
\text { stabilized }\end{array}$ & $\begin{array}{l}\text { Orbit transfer } \\
\text { instability }\end{array}$ & Unexpected liquid slosh modes \\
\hline 1987 & Zenith Star & $\begin{array}{l}\text { Attitude } \\
\text { thrusters }\end{array}$ & $\begin{array}{l}\text { Nonrepeatable modal } \\
\text { frequencies for } \\
\text { identical parts }\end{array}$ & Variability of materials and geometry \\
\hline 1989 & Galileo & $\begin{array}{l}\text { Spin } \\
\text { stabilized }\end{array}$ & $\begin{array}{l}\text { Schedule impacted, } \\
\text { system identification } \\
\text { added }\end{array}$ & $\begin{array}{l}\text { Structural frequencies close to control bandwidth, } \\
\text { model uncertain }\end{array}$ \\
\hline 1989 & Magellan & $\begin{array}{l}\text { Attitude } \\
\text { thrusters }\end{array}$ & $\begin{array}{l}\text { Design cost and } \\
\text { schedule impact, } \\
\text { redesign control law }\end{array}$ & $\begin{array}{l}\text { Design of solar panels ignored attitude control system } \\
\text { during solid rocket motor burn }\end{array}$ \\
\hline 1990 & $\begin{array}{l}\text { Harbert Space } \\
\text { Telescope }\end{array}$ & $\begin{array}{l}\text { Attitude } \\
\text { thrusters }\end{array}$ & Vibrations excessive & $\begin{array}{l}\text { "Jitter"phenomenon attributed to thermally-induced } \\
\text { vibrations of FRUSA }\end{array}$ \\
\hline 1991 & $\begin{array}{l}\text { Upper Atmosphere } \\
\text { Research Satellite } \\
\text { (UARS) }\end{array}$ & $\begin{array}{l}\text { Attitude } \\
\text { thrusters }\end{array}$ & Vibrations excessive & $\begin{array}{l}\text { "Thermal snap"disturbances during eclipse transitions } \\
\text { attributed to rapid thermal bending of large single } \\
\text { wing solar array }\end{array}$ \\
\hline 1992 & TOPEX & $\begin{array}{l}\text { Attitude } \\
\text { thrusters }\end{array}$ & Vibrations excessive & $\begin{array}{l}\text { "Thermal snap"disturbances during eclipse transitions } \\
\text { attributed to rapid thermal bending of large single } \\
\text { wing solar array }\end{array}$ \\
\hline 1994 & INSAT-II & $\begin{array}{l}\text { Attitude } \\
\text { thrusters }\end{array}$ & Vibrations excessive & Thermal bending of solar array and solar sail mast \\
\hline 1995 & Mir space station & $\begin{array}{l}\text { Attitude } \\
\text { thrusters }\end{array}$ & Vibrations excessive & $\begin{array}{l}\text { Thermally-Induced Structural Motions of a solar array } \\
\text { wing on the Kvant-II module observed orbital eclipse } \\
\text { transitions }\end{array}$ \\
\hline 1996 & Spartan & $\begin{array}{l}\text { Spin } \\
\text { stabilized }\end{array}$ & Unstable roll & $\begin{array}{l}\text { Thrusters and gyros noncollocated with flexible panels } \\
\text { between them }\end{array}$ \\
\hline 1996 & $\begin{array}{l}\text { Space Flyer Unit } \\
\text { (SFU) }\end{array}$ & $\begin{array}{l}\text { Attitude } \\
\text { thrusters }\end{array}$ & Vibrations excessive & $\begin{array}{l}\text { Thermally-Induced Structural Motions of flexible } \\
\text { blanket solar array during orbital eclipse transitions }\end{array}$ \\
\hline 1997 & Adeos-1 & $\begin{array}{l}\text { Attitude } \\
\text { thrusters }\end{array}$ & $\begin{array}{l}\text { Unstable roll, } \\
\text { depleted fuel }\end{array}$ & $\begin{array}{l}\text { Thermally-Induced Structural Motions of flexible } \\
\text { blanket solar array, Failure of solar array due to } \\
\text { thermal expansion and contraction solar cell blanket } \\
\text { beyond limits of solar array tension control }\end{array}$ \\
\hline 1999 & Shen Zhou-1 & $\begin{array}{l}\text { Attitude } \\
\text { thrusters }\end{array}$ & $\begin{array}{l}\text { Limit cycle, but } \\
\text { within specification }\end{array}$ & $\begin{array}{l}\text { Structural frequencies close to control bandwidth, } \\
\text { model uncertain }\end{array}$ \\
\hline 2001 & Shen Zhou-2 & $\begin{array}{l}\text { Attitude } \\
\text { thrusters }\end{array}$ & $\begin{array}{l}\text { Limit cycle, but } \\
\text { within specification }\end{array}$ & $\begin{array}{l}\text { Structural frequencies close to control bandwidth, } \\
\text { model uncertain }\end{array}$ \\
\hline 2001 & Mir space station & $\begin{array}{l}\text { Attitude } \\
\text { thrusters }\end{array}$ & $\begin{array}{l}\text { Limit cycle, but } \\
\text { within specification }\end{array}$ & $\begin{array}{l}\text { Structural frequencies close to control bandwidth, } \\
\text { model uncertain }\end{array}$ \\
\hline 2002 & Shen Zhou-3 & $\begin{array}{l}\text { Attitude } \\
\text { thrusters }\end{array}$ & $\begin{array}{l}\text { Limit cycle, but } \\
\text { within specification }\end{array}$ & $\begin{array}{l}\text { Structural frequencies close to control bandwidth, } \\
\text { model uncertain }\end{array}$ \\
\hline 2002 & Shen Zhou-4 & $\begin{array}{l}\text { Attitude } \\
\text { thrusters }\end{array}$ & $\begin{array}{l}\text { Limit cycle, but } \\
\text { within specification }\end{array}$ & $\begin{array}{l}\text { Structural frequencies close to control bandwidth, } \\
\text { model uncertain }\end{array}$ \\
\hline 2003 & Shen Zhou-5 & $\begin{array}{l}\text { Attitude } \\
\text { thrusters }\end{array}$ & $\begin{array}{l}\text { Limit cycle, but } \\
\text { within specification }\end{array}$ & $\begin{array}{l}\text { Structural frequencies close to control bandwidth, } \\
\text { model uncertain }\end{array}$ \\
\hline 2005 & Shen Zhou-6 & $\begin{array}{l}\text { Attitude } \\
\text { thrusters }\end{array}$ & $\begin{array}{l}\text { Limit cycle, but } \\
\text { within specification }\end{array}$ & $\begin{array}{l}\text { Structural frequencies close to control bandwidth, } \\
\text { model uncertain }\end{array}$ \\
\hline 2006 & Express-AM11 & $\begin{array}{l}\text { Spin } \\
\text { stabilized }\end{array}$ & $\begin{array}{l}\text { Orbit transfer } \\
\text { instability }\end{array}$ & Space debris impact \\
\hline 2008 & Shen Zhou-7 & $\begin{array}{l}\text { Attitude } \\
\text { thrusters }\end{array}$ & $\begin{array}{l}\text { Limit cycle, but } \\
\text { within specification }\end{array}$ & $\begin{array}{l}\text { Structural frequencies close to control bandwidth, } \\
\text { model uncertain }\end{array}$ \\
\hline
\end{tabular}


not used much in the field of dynamics of flexible multi-body system because of its "singularity" problem.

The absolute nodal coordinate method which is proposed by Shabana (1996), does not use any hypothesis, direct build a finite element model which can accurately describe the finite element model of the flexible body with large rotation and deformation. Compared with the traditional method of modeling flexible multi-body system, this method which unified describes flexible body's rigid body motion and elastic deformation by interpolation function in the inertial coordinate system is very suitable to describe the dynamics with both large rotation and large deformation. So, it is considered to be a milestone in the history of the development of dynamics of flexible multibody systems. Finite element study includes the beam element, plate element and membrane element. Beam element types include variable length tether element, three node plane shear beam, curved beam element, twodimensional ANCF shear deformation beam element with 16 free degrees; Membrane element ${ }^{[5]}$ was used in the analysis of complex membrane system under the condition of large deformation and fold; Triangular thin plate element breaks through the limitation of element to solve the problem of rectangular plate, and make it probably to solve the plate in arbitrary shapes.

Shabana $^{[6]}$ provided a simple planar beam element and beams and plates could be treated as isoparametric elements; Berzeri ${ }^{[7]}$ presented four different planar beam elements and developed simple and accurate elastic force models that could be used in the absolute nodal co-ordinate formulation for the analysis of two-dimensional beams; Based on the theory of continuous medium mechanics, Omar $^{[8]}$ provided a kind of two-dimensional shear deformable beam element; Kerkkanen ${ }^{[9]}$ provided a kind of linear beam finite element which can effectively reduce the unlocking problem. Futher more, Dufva and Sopanen ${ }^{[10,11]}$ provided new kind of three-dimensional beam element and two-dimensional shear deformable beam element based on the absolute nodal coordinate formulation; Garcia-Vallejo and Mikkola ${ }^{[12]}$ introduced a new absolute nodal coordinatebased finite element. The introduced element used redefined polynomial expansion together with a reduced integration procedure. The performance of the introduced element was studied by means of certain dynamic problems. The element exhibits a competent convergence rate and it did not suffer from the previously mentioned locking effects; Sugiyama [13] developed a curved beam element for the analysis of large deformation of flexible multi-body systems using the absolute nodal coordinate formulation. It was employed to alleviate the locking associated with the cross-section deformation; Pengfei et $\mathrm{al}^{[14]}$.examined the effect of the order of interpolation on the modes of deformation of the beam cross section using ANCF finite elements. And a new twodimensional shear deformable ANCF beam element was developed. The new finite element employs a higher order of interpolation, and allowed for new cross section deformation modes that could not be captured using previously developed shear deformable ANCF beam elements. Cheng Liu and Qiang Tian ${ }^{[15]}$ proposed a new spatial curved slender-beam finite element and a new cylindrical shell finite element in the frame of gradient-deficient Absolute Nodal Coordinate Formulation (ANCF), four case studies including both static and dynamic problems were given to validate the proposed beam and cylindrical shell elements of gradient-deficient ANCF; Mikkola ${ }^{[16]}$ discussed the generalization of the formulation to the case of shell elements and presented two different plate elements as examples of the implementation of the proposed method; Dmitrochenko ${ }^{[17]}$ proposed a way to generate new finite elements in the absolute nodal coordinate formulation (ANCF) and use a generalization of displacement fields and degrees of freedom (d.o.f.) of ordinary finite elements used in structural mechanics; Yoo et al. ${ }^{[18]}$ show the validity of the absolute nodal coordinate formulation (ANCF) by comparing to the real experiments; Dmitrochenko ${ }^{[19]}$ introduced two triangular plate elements based on the absolute nodal coordinate formulation (ANCF). Previous plate developments in the absolute nodal coordinate formulation have focused on rectangular elements that are difficult to use when arbitrary meshes need to be described. The elements introduced had overcome this problem and represented an important addition to the absolute nodal coordinate formulation.

On the research of numerical algorithm, Grzegorz ${ }^{[20]}$ devoted to the analysis of selected differential-algebraic equations (DAEs) of index 3 solvers, which were applied to simulations of simple mechanisms; Orzechowski ${ }^{[21]}$ proposed the new integral method which could analyze the beam with circular cross section obtained by the absolute nodal coordinate method, overcoming constraints which beam cross section shape is rectangular when integrals for beam by standard space Gauss Legendre integral method; Hussein and Negrut ${ }^{[22]}$ showed that the CPU time associated with the HHT-I3 integrator did not change significantly when the stiffness of the bodies increases, while in the case of the explicit Adams method the CPU time increased exponentially. The fundamental differences between the solution procedures used with the implicit and explicit integrations were also discussed; Hiroki Yamashita ${ }^{[23]}$ obtained numerical convergence of finite element solutions by using the B-spline approach and the absolute nodal 
coordinate formulation; Chijie ${ }^{[24]}$ discussed about the dynamic and thermal analyses of flexible structures in orbit; Souh ${ }^{25]}$ developed a new plane beam dynamic formulation for constrained multibody system dynamics; Garcia-Vallejo ${ }^{[26]}$ developed a new procedure for evaluating the elastic forces, the elastic energy and the jacobian of the elastic forces in the absolute nodal coordinate formulation. For this procedure, it was fundamental to use some invariant sparse matrices that were integrated in advance and have the property of transforming the evaluation of the elastic forces in a matrix multiplication process. The use of the invariant matrices avoids the integration over the volume of the element for every evaluation of the elastic forces. Great advantages could be achieved from these invariant matrices when evaluating the elastic energy and calculating the jacobian of the elastic forces as well; Ting $\mathrm{Pi}$ and Yunqing Zhang ${ }^{[27]}$ proposed a new method to deduce system sensitivity equations. With this approach, the system sensitivity equations were constructed by assembling the element sensitivity equations with the help of invariant matrices, which resulted in the advantage that the complex symbolic differentiation of the dynamic equations was avoided when the flexible multibody system model was changed. Besides that, the dynamic and sensitivity equations formed with the proposed method could be efficiently integrated using HHT-I3 method, which made the efficiency of the direct differentiation method comparable to that of the adjoint variable method when the number of design variables was not extremely large.

On the research of the constitutive model, it mainly includes the research of nonlinear constitutive model and elastic material constitutive model. Yunqing Zhang and Qiang $\operatorname{Tian}^{[28]}$ employed a new finite element formulation for dynamics analysis of a viscoelastic flexible multibody system. The viscoelastic constitutive equation used to describe the behavior of the system was a three-parameter fractional derivative model. Based on continuum mechanics, the three-parameter fractional derivative model was modified and the proposed new fractional derivative model could reduce to the widely used elastic constitutive model, which met the continuum mechanics law strictly for pure elastic materials.

Maqueda and LG $\mathrm{M}^{[29,30]}$ presented beam models that employ general nonlinear constitutive equations using finite elements based on the nonlinear absolute nodal coordinate formulation. These results showed that the use of nonlinear constitutive models could significantly enhance the performance and improve the computational efficiency of the finite element models based on the absolute nodal coordinate formulation. The results also showed that when linear constitutive models were used in the large deformation analysis, singular configurations were encountered and basic formulas such as Nanson's formula were no longer valid; Sugiyama ${ }^{[31]}$ investigated the performance of different numerical integration methods in the dynamic analysis of large elasto-plastic deformation problems. It was shown that all these methods, in the case of convergence, yield a solution that satisfies the principle of work and energy without the need of taking any special measures; Kübler L and Eberhard ${ }^{[32]}$ proposed an approach in order to consider structural damping using a viscous extension for hyper-elastic materials of neo-Hooke type; Garcia-Vallejo and Valverde ${ }^{[33]}$ presented an internal damping model based on linear viscoelasticity for the absolute nodal coordinate formulation and proposed a practical procedure for estimating the parameters that govern the dissipation of energy.

On the research of application, it focuses on the large deformation analysis in the multi-body dynamics ${ }^{[34]}$ and the related engineering application ${ }^{[35]}$. Gerstmayr et al. ${ }^{[34]}$ provided a comprehensive review of the finite element absolute nodal coordinate formulation, which could be used to obtain efficient solutions to large deformation problems of constrained multibody systems. In particular, important features of different types of beam and plate elements that had been proposed since 1996 were reviewed; Laith K and Abbas ${ }^{[36]}$ carried out aeroelastic analysis of a plate subjected to the external supersonic airflow. A 3-D rectangular plate element of variable thickness based on absolute nodal coordinate formulation (ANCF) had been developed for the structural model; Tian et al. ${ }^{\left[{ }^{[7]}\right.}$ presented a new computational methodology for modeling and analysis of planar flexible multibody systems with clearance and lubricated revolute joints based on the absolute nodal coordinate formulation (ANCF); Liu et al. ${ }^{[38]}$ studied the dynamics and control of a rigid-flexible multibody system with multiple cylindrical clearance joints via the Absolute Coordinate Based (ACB) method that combined the Natural Coordinate Formulation (NCF) describing rigid bodies and the Absolute Nodal Coordinate Formulation (ANCF) describing flexible bodies; Majda et al. ${ }^{[39]}$ studied modelling of planar flexible beams undergoing large overall motions based on finite element (FE) technique; Considering the effects of the clearances and lubrication in the system spherical joints, Tian et al. ${ }^{[40]}$ presented a computational methodology for analysis of spatial flexible multibody systems; Qiang Tian and Yanlei Sun ${ }^{[41]}$ proposed a new methodology for the dynamic analysis of rigid-flexible multibody systems with Elasto Hydro Dynamic (EHD) lubricated cylindrical joints.

Ahmed et al. ${ }^{[42]}$ demonstrated the use of the absolute nodal coordinate formulation (ANCF) in the integration of 
finite element (FE) and multibody system (MBS) algorithms for modeling the rigid body contact and the ligament flexibility in bio-mechanics applications; Dmitrochenko ${ }^{[43]}$ discussed a family of structural finite elements using a modern absolute nodal coordinate formulation (ANCF) with many applications; Difeng Hong ${ }^{[44]}$ proposed a dynamic model of a linear medium with mass flow, such as traveling strings, cables, belts, beams or pipes conveying fluids; Tang studied $^{[45]}$ the dynamics of variable-length tethers using a flexible multibody dynamics method. The governing equations of the tethers were derived using a new, hybrid Eulerian and Lagrangian framework, by which the mass flow at a boundary of a tether and the length variation of a tether element were accounted; Zhenxing Shen et al. ${ }^{[46]}$ conducted a coupled thermal-structural analysis based on the EulerBernoulli beam model within a framework of Absolute Nodal Coordinate Formulation; Ayman and Nada ${ }^{[47]}$ investigated a way to generate new finite element in the ANCF for laminated composite plates.

However, the absolute nodal coordinate method also has some shortcomings. According to the spacecraft structure with flexible appendages system for "large flexible multi-body plate structure", it is difficult to bear to solve scale the problem about coupled dynamics analysis and control based on the dynamic modeling of the absolute nodal coordinate method. Because this method uses the consistent quality finite element to discrete flexible body discrete objects, it does not distinguish between rigid motion and elastic deformation, so that even the small deformation should be dealt with the method of large deformation.

The research application of the hybrid coordinate method is wide, it builds a floating coordinate system for flexible component firstly, and regards the position and shape of the component as superposition between the wide range of motion of floating coordinate system and respect to the coordinate deformation. It comes out a way to establish the dynamics model which used the rigid body coordinate in the floating coordinate system with a wide range and the flexible body coordinates of the nodes(or modal coordinates). Although this method considering the interaction between the elastic deformation of components and the motion in a wide range, the coupling process which is between the rigid body motion with a wide range under low frequency and flexible body deformed motion under high frequency. So, it only applicable to describe the wide range motion of the rigid body under low velocity. With the flexible spacecraft and flexible mechanical arm's flexible structure with "large scale, large deformation, rigid flexible coupling, flexible-flexible coupling" movement developed in the engineering technology of lightweight, high speed, heavy load and high precision, the dynamic simulation of the traditional hybrid coordinate method modeling theory has been failed and completely got wrong conclusions. So it is very necessary to establish accurately coupling dynamics model which describes the flexible structure coupling system with "wide range, large deformation, rigid-flexible coupling and flexible-flexible coupling" movement.

Integrated modeling method is a way which researchers proposed integrated all kinds of methods in recent years, such as absolute nodal coordinate method of floating coordinate system. Foreign scholar, called Garciar Vallejo, using the absolute nodal coordinate method modeling theory in floating coordinate system, studies the dynamic stiffness problem of plane beam that its large range of motion is known. The domestic scholars such as Liu Jinyang have been using the absolute nodal coordinate method modeling theory in floating coordinate system to establish the rigid flexible coupling dynamic model of flexible "beam" with a large range of space motion under the small deformation assumption. However, as for the spacecraft's "large flexible multi-body plate structure system, there is few kinetic modeling studies which based on the absolute nodal coordinate method reported. And in the research ofmulti-body dynamics modeling of spacecraft, especially for the dynamic modeling of "plate structure system", often regards "plate structure system" as "beam structure system" to solve, such as a large solar array of satellite. Sun wing structure vibration including bending vibration and torsional vibration are both obvious, so the way what to regard it as its "beam structure system" to solve has obvious shortcomings apparently.

Discrete mechanism of flexible body is one of the basic problems in flexible structure coupling dynamics under large range, large deformation, rigid-flexible coupling and flexible-flexible coupling movement. At present, the discrete methods can be roughly divided into three categories: the assumed mode method, the finite element method and modal synthesis method, the component mode synthesis method. The assumed mode method, which is based on the Rayleigh-Ritz method, expressed the deformation field of flexible body as a linear combination of the modal function and modal coordinates. But this method is limited for the dynamics analysis of flexible structure such as uniform beam and rectangular plate elements which has simple structure and regular shape. The finite element method program is good, but for large and complex systems, especially for the solution scale of coupling dynamics analysis and control of flexible structure in large overall motions is unbearable. Therefore, the finite element method should be combined with the modal synthesis technique, transformed the modal coordinate by modal analysis and the kinetic equation of and 
modal truncation technique for node displacement to greatly reduce the solution scale. The component mode synthesis method segments the research system into several parts, builds modal sat and modal coordinates of components, and then, connects components independent modal coupling by the connection of parts interface, assembles the dynamic equations of the system, next, lets the modal coordinate of system dynamics equations to return to the physical coordinates by the corresponding transformation, finally, obtains the desired result. The method, which makes full use of the modal synthesis technique, can greatly reduce the solving scale.

However, no matter which of the above methods, we need to use the modal analysis technology in order to reduce the scale of solution. And there are many difficulties in analyzing coupling dynamics of motion flexible structure in the "big range, large deformation, rigid-flexible coupling, flexible -flexible coupling" conditions. First of all, only the component is linear in floating coordinate, can we use modal analysis method. Secondly, as a result of movement of the flexible structure in "large scale, large deformation, rigid-flexible coupling, flexible-flexible coupling" is a kind of variable structure system, adjacent components' transmission inertia by constraint and rigid influence of spatial configuration and degree of freedom is time-varying, and components motion in the large range is also time-varying, so the true frequency and mode of each component in system are dynamic and transient. It is not affordable to cost CPU if we get iteration process of average eigenvalue system equations which is in a few time.

The key to ensure the accuracy of modal analysis is weather each modal which we selected can response the actual deformation of components. At present, we can only establish a system which regard components' static mode without a wide range of motion and the superposition of static modes as their assumed modes in "large scale, large deformation, rigid-flexible coupling, flexible-flexible coupling" motion at arbitrary time when we haven't found the real modal of dynamic boundary component yet. This system can only modal-analyze the static position, so we can just get the accurate solutions in the case of low speed. And it is difficult to make quantitative estimates of the accuracy of the solution, especially for the numerical instability, and it is difficult to determine what caused it.

In recent years, scholars around the world have used different theoretical analysis and numerical simulation methods to solve the frequencies and mode shapes of system. At present, they have confirmed that it will have a greater error if we use corresponding model of flexible structure without large overall motions to discrete the deformation of flexible structure in large overall motions when the components moves with high speed in a wide range. This way even can not reflect the real vibration mode and vibration frequency of structures.

DROMM modeling method ${ }^{[48]}$ is proposed by the project applicant based on the lumped parameter modeling method. This method is not only considers the disturbance of modal information, but also solves the existing problems in reducing the cost of models which is used in flexible structure models, discreteness, and solving model parameters.

Fractional order calculus is a generalization of the integer order calculus, and it has many outstanding advantages compared with the integer order calculus: First of all, the integer order calculus only depends on the local characteristics of function, and fractional order calculus consider the overall information of function by weighted, so, in many applications of fractional order model can more accurately describe the dynamic response of the real system; Secondly, when describing the object with fractional characteristics by fractional order, we can not only do better in revealing the nature and behavior of objects, but also overcome the disadvantages which the same part between classical integer order calculus model theory and engineering application is few. This model can obtain a wonderful effect by few parameters, too. Thirdly, in describing the complex physics mechanical problems, the physical meaning of fractional order model is clearer and representation of it is more concise compared with the integer order model; Finally, the fractional order control expands the degree of freedom control, it can get a better control performance. It also has memory function, which not only ensure that the historical information on the present and future, but also improve the control.

\section{Research Progress Of Flexible Spacecraft's Structure Vibration-attitude Coordinated Control}

Flexible spacecraft's structure vibration-attitude coordinated control includes two aspects: the vibration control of flexible structure and attitude control of flexible spacecraft.

Structural vibration control can be divided into passive vibration control, semi-active control and active vibration control. Active vibration control is a hot research topic at present. Active vibration control needs to add many main structure resonance frequences to the design of control system. At the same time, active vibration control needs to ensure that the structure model permits the existence of 
multiple error.

Traditional algorithms of active vibration control has speed feedback control ${ }^{[49]}$, LQR control ${ }^{[50]}$, proportional feedback control $^{[51]}$. However, in the design of feedback control strategy, active control method based on traditional control algorithm is not only easy to cause spillover instability, but also easy to lead serious structure vibration because of ignoring the model information. Furthermore, the premise of the vibration control based on traditional control algorithm is accurate mathematical model, and the real control system is very difficult to establish the precise mathematical model. And intelligent control theory can solve the controller design problem of the uncertainty system model. So, it will become the research trend that intelligent control theory is applied to structural vibration control. Intelligent vibration control research began in the 80's of last century, such as the space simulation laboratory of Hughes Co launched the experiment of solar array expansion and experimental study on vibration; Russia effectively suppressed flexible vibration of the solar panels by the intelligent control technology and save $90 \%$ spacecraft fuel in 1987.Intelligent vibration control research mainly on smart actuator and Application Research of intelligent control algorithm. In the research of intelligent actuator, it has photo induced telescopic actuator $^{[52]}$, piezoelectric actuator ${ }^{[53]}$, and so on. In the research of intelligent control algorithm, it has fuzzy control algorithm, neural network-fuzzy control algorithm ${ }^{[52]}$ and robust control algorithm. In the research of vibration control, it has few achievements on vibration control of large-scale multi-adagio structure intelligent systems; Reza et al. ${ }^{[54]}$ presented an active vibration control (AVC) incorporating active piezoelectric actuator and self-learning control for a flexible plate structure; Mat Darus ${ }^{[5]}$ realized the soft computing adaptive active control of flexible plate vibration control system. Chen Long-Xiang ${ }^{[56]}$ did experimental study of delayed feedback control for a flexible plate Zhi-cheng Qiu ${ }^{[57]}$ researched on sliding mode active vibration control of flexible piezoelectric cantilever plate integrated gyroscope; Ma, K. and Ghasemi-Nejhad ${ }^{[58]}$ investigated simultaneous adaptive positioning and vibration control of a flexible active composite manipulator with two piezoelectric patches; Kumar and Singh $^{[59]}$ presented experimental adaptive identification and control of smart structures using neural networks based on system classification technique. An inverted L-structure with surface-bonded piezoceramic sensors/actuators was used for analysis; Lin J and L WZ ${ }^{[60]}$ presented a novel resonant fuzzy logic controller (FLC) to minimize structural vibration using collocated piezoelectric actuator/sensor pairs; Qiu et al. ${ }^{[61]}$ did experimental study on sliding mode variable structure vibration control for piezoelectric cantilever plate vibration control.

Flexible spacecraft attitude control has some typical problems in the flexible spacecraft attitude control. They are parameter uncertainty of inertia ${ }^{[62]}$, disturbance torque with all kinds of space environment or not ${ }^{[63]}$, the vibration of flexible appendages ${ }^{[64]}$, actuator saturation / nonlinear effects of dead zone input ${ }^{[65]}$ actuator dynamics, etc. Attitude control theory and method has gone through two stages which are the traditional control method and intelligent control technology. In the traditional design method of the control system, the feedback regulation what we designed in spacecraft attitude control do mostly not considering the structure of system or the factors of parameter uncertainty. We just depends on the dynamic mathematical equations which we got it by simplified abstraction. So,it can only permit that its bandwidth of closed-loop system is much more shorter than the flexible frequency in order to avoid the instability what interaction between control / structures caused. The bandwidth of attitude control system which is elected by traditional experience and methods is shorter than the $1 / 6$ of flexible frequency in order to obtain the stability margin. This method can ensure the flexible modes are all stable gain. The traditional design method provides robustness by controlling bandwidth of the system, but it needs to sacrifice the system performance. Improving the system performance also needs to control the bandwidth to the minimum structure modal frequency at least. So, the traditional design method has certain limitations. The common traditional control algorithm are PWM control $\operatorname{method}^{[66]}$, LQR control method ${ }^{[67]}$, integral feedback $\operatorname{control}^{[68]}$, PID control method ${ }^{[69]}$, adaptive control ${ }^{[70]}$, and so on. However, the modern spacecraft structure is a typical uncertain system, because of its low frequency, modal density and model errors. This kind of system has higher requirements in the pointing accuracy and stability of the attitude motion, so it is a difficult control problem. The control effect of the traditional control system is not ideal, and sometimes it even could not ensure the stability of system operation. Therefore, scholars both at home and abroad has widely carried out researches on intelligent control theory and method, in order to achieve the requirements of the system performance and the control precision. Attitude control method what based on the design theory and method of intelligent control has network control ${ }^{[71]}$, adaptive sliding mode control ${ }^{[72]}$, robust control ${ }^{[73]}$, neural network-fuzzy $\operatorname{control}^{[74]}$, etc. Binglong et al. ${ }^{[72]}$ aimed to address the robust control problem of rigid spacecraft attitude maneuvers in the presence of inertia matrix uncertainty and external disturbance. A back-stepping based adaptive sliding mode control (B-ASMC) design was proposed as a solution, 
where the upper bounds of the parametric uncertainty and disturbance are not required in advance; Kunfeng and Lu $\mathrm{Y} \mathrm{X}{ }^{[75]}$ researched adaptive attitude tracking control for rigid spacecraft with finite-time convergence.

\section{Control of fractional order system}

In the current research of nonlinear large-scale system, we carried out a lot of research work contacting with the theory of intelligent control for its strong coupling characteristics ${ }^{[76]}$, uncertain problem $^{[77]}$, time delay problem ${ }^{[78]}$, the dead zone problem $^{[79]}$, the noise problem ${ }^{[80]}$, the control input with mismatched interconnections ${ }^{[81]}$. When there are some problems in the stability and robustness of a system, we often improve these properties by adding control mechanisms. However, when the control strategy is introduced, the uncertainty caused by all kinds of bias and error of control strategy, has became another interference factors of the system. For example, in the structural vibration-attitude coupled control of spacecraft, due to the addition of control means, its deviation will bring a certain degree of uncertainty. How to overcome the model uncertainty caused by interference, which became the control system non-vulnerability. As a result, fractional order large-scale control system is possible way to solve above problem.

\section{Recommended Future Research}

The control of flexible multi-body system composed of plate-like structures has application to control of space systems, aircraft, to name a few. Flexible multi-body system composed of plate-like structures is typically lightweight and highly flexible. These systems have distributed-parameter dynamics; their natural damping is very small; they have many densely packed low-frequency modes; and their model parameters are uncertain. Moreover, performance requirements such as pointing accuracy, shape control, and bandwidth are very stringent and make the problem of structural vibration more acute. Examples of flexible multibody system composed of plate-like structures include a variety of space structures ranging from large solar panels to very complex space stations.

The future research will be concerned with the intelligent high precision shape and vibration control of flexible multi-body system composed of plate-like structures. The dynamics of flexible multi-body system composed of platelike structures is uncertain due to factors such as high nonlinearity, consideration of higher modal frequencies, high dimensionality, multiple inputs and outputs, operational constraints, as well as unexpected failures of sensors and/ or actuators. The research will be addressed the modeling of these flexible multi-body systems composed of plate-like structures and the associated vibration and shape control system new type intelligent controller design technique.

Most importantly, as the development of aircrafts, huge flexible multi-body systems have become a research focus in the field of flexible multi-body dynamics and control, such as Space Mirror and Space Solar Power Station. The technologies of intelligent structure vibration-attitude coordinated control of spacecraft composed of flexible multi-body system will speed up the development of manmade vehicles, reduce cost and risk of operation, and enhance support for future space activities greatly. No doubt that it will play a key role in future research for spacecraft and further exploitation of the outer space.

\section{Acknowledgement}

This workwas supported byproject "Research on Intelligent Integrated Control of Coupling between Space Solar Power Station Structure Vibration and Attitude Control"(BYB22) ,Exploration and Practice of 'Theory+Interesting+Research' Innovative Teaching Mode"(YJS2014-11), "Study of fractional order coupled structure vibration-attitude dynamic and control of spacecraft. (L2015414)".

\section{References}

[1] S. Glasstone, Sourcebook on the Space Sciences. 1965.

[2] P. C. Hughes, Spacecraft Attitude Dynamics, Dover Publications, 1986.

[3] L. P. W, "Spacecraft Attitude Dynamics and Control-A Personal Perspective on Early Developments", J. Guid. Control. Dyn., Vol. 19, 1986, pp. 129-134.

[4] M. Balas, "Trends in large space structure control theory: fondest hopes, wildest dreams", Autom. Control. IEEE Trans., Vol. 27, No. 3, 1982, pp. 522-535.

[5] H. H. Cheng Liu, Qiang Tian, and Dong Yan, "Dynamic analysis of membrane systems undergoing overall motions, large deformations and wrinkles via thin shell elements of ANCF", Com put. Methods Appl.Mech.Engrg., Vol. 258, 2013, pp. 81-95.

[6] E. J. L. Shabana, and A A, Hussien, H. A., "Application of the absolute nodal coordinate formulation to large rotation and large deformation problems", J. Mech. Des., Vol. 120, No. 2, 1998, pp. 188-195.

[7] S. A. A. and Berzeri, M., "Development of simple models for the elastic forces in the absolute nodal coordinate formulation", J. Sound Vib., Vol. 235, No. 4, 2000, pp. 
539-565.

[8] S. A. A., Omar, M. A., "A two-dimensional shear deformable beam for large rotation and deformation problems", J. Sound Vib., Vol. 243, No. 3, 2001, pp. 565-576.

[9] M. A. M., Kerkkanen K. S. and Sopanen, J. T., "A linear beam finite element based on the absolute nodal coordinate formulation", J. Mech. Des., Vol. 127, No. 4, 2005, pp. 621-630.

[10] M. A. M., Dufva, K. E. and Sopanen, J. T., "Threedimensional beam element based on a cross-sectional coordinate system approach", Nonlinear Dyn., Vol. 43, No. 4, 2006, pp. 311-327.

[11] M. A. M., Dufva, K. E. and Sopanen, J. T., "A twodimensional shear deformable beam element based on the absolute nodal coordinate formulation", J. Sound Vib., Vol. 280, No. 3, 2005, pp. 719-738.

[12] E. J. L., Garcia-Vallejo, D. and Mikkola, A. M., "A new locking-free shear deformable finite element based on absolute nodal coordinates", Nonlinear Dyn., Vol. 50, No. 1, 2007, pp. 249-264.

[13] S. Y. and Sugiyama, H., "A curved beam element in the analysis of flexible multi-body systems using the absolute nodal coordinates", J. Multi-body Dyn., Vol. 221, No. 2, 2007, pp. 219-231, 2007.

[14] A. A. S., Pengfei, Li, and Florentina, M. Gantoi, "Higher order representation of the beam cross section deformation in large displacement finite element analysis", J. Sound Vib., Vol. 330, 2011, pp. 6495-6508.

[15] H. H., Cheng Liu, and Qiang Tian, "New spatial curved beam and cylindrical shell elements of gradient-deficient Absolute Nodal Coordinate Formulation", Nonlinear Dyn, Vol. 70, 2012, pp. 1903-1918.

[16] S. A. A. and Mikkola, A. M., "A non-incremental finite element procedure for the analysis of large deformation of plates and shells in mechanical system applications", Multibody Syst. Dyn., Vol. 9, No. 3, 2003, pp. 283-309.

[17] P. D. Y. and Dmitrochenko, O. N., "Generalization of plate finite elements for absolute nodal coordinate formulation", Multibody Syst. Dyn., Vol. 10, No. 1, 2003, pp. $17-43$.

[18] Yoo, W., Lee, J. and Park, S., "Large deflection analysis of a thin plate: computer simulations and experiments", Multibody Syst. Dyn., Vol. 11, No. 2, 2004, pp. 185-208.

[19] M. A. and Dmitrochenko, O., "Two simple triangular plate elements based on the absolute nodal coordinate formulation", J. Comput. Nonlinear Dyn., Vol. 3, No. 4, 2008, pp. 12-41.

[20] J. F. Grzegorz ORZECHOWSKI, “INTEGRATION OF THE EQUATIONS OF MOTION OF MULTIBODY SYSTEMS USING ABSOLUTE NODAL COORDINATE FORMULATION", Acta Mech. Autom., Vol. 6, No. 2, 2012, pp. 75-83.
[21] G. ORZECHOWSKI, "ANALYSIS OF BEAM ELEMENTS OF CIRCULAR CROSS SECTION USING THE ABSOLUTE NODAL COORDINATE FORMULATION", Arch. Mech. Eng., Vol. 12, No. 3, 2012, pp. 283-296.

[22] S. A. Hussein, B. and Negrut, D., "Implicit and Explicit Integration in the Solution of the Absolute Nodal Coordinate Differential/Algebraic Equations", Nonlinear Dyn., No. 54, 2008, pp. 283-296.

[23] H. S. Hiroki Yamashita, "Numerical convergence of finite element solutions of nonrational B-spline element and absolute nodal coordinate formulation", Nonlinear Dyn, Vol. 67, 2012, pp. 177-189.

[24] Chijie, L., "Dynamic and thermal analyses of flexible structures in orbit", [PhD Dissertation].Storrs, University of Connecticut, 2006.

[25] B. Souh, "Absolute nodal coordinate plane beam formulation for multibody systems dynamics", Multibody Syst Dyn, Vol. 12, 2012, pp. 156-166.

[26] E. Garcia-Vallejo D, Mayo J, "Efficient Evaluation of the Elastic Forces and the Jacobian in the Absolute Nodal Coordinate Formulation", Nonlinear Dyn., No. 35, 2004, pp. 313-329.

[27] L. C. Ting Pi, Yunqing Zhang, "First order sensitivity analysis of flexible multibody systems using absolute nodal coordinate formulation", Multibody Syst Dyn, Vol. 27, 2012, pp. 153-171.

[28] L. C. Yunqing Zhang, Qiang Tian, "Simulation of a viscoelastic flexible multibody system using absolute nodal coordinate and fractional derivative methods", Multibody Syst Dyn, Vol. 21, 2009, pp. 281-303.

[29] S. A. Maqueda LG, "Poisson modes and general nonlinear constitutive models in the large displacement analysis of beams", Multibody Syst. Dyn., No. 18, 2007, pp. 375-396.

[30] M. LG, "Use of nonlinear constitutive models in the absolute nodal coordinate formulation", [PhD Dissertation], Chicago:University of Illinois at Chicago, 2008.

[31] S. A. Sugiyama H, "On the Use of Implicit Integration Methods and the Absolute Nodal Coordinate Formulation in the Analyssis of Elasto-Plastic Deformation Problems", Nonlinear Dyn., No. 37, 2004, pp. 245-270.

[32] G. J. Kübler L, and Eberhard, P., "Flexible Multibody Systems with Large Deformations and Nonlinear Structural Damping Using Absolute Nodal Coordinates", Nonlinear Dyn., No. 34, 2003, pp. 31-52.

[33] J. D. Garcia-Vallejo D, and Valverde J, "An Internal Damping Model for the Absolute Nodal Coordinate Formulation", Nonlinear Dyn., No. 42, 2005, pp. 347-369.

[34] J. Gerstmayr, H. Sugiyama, and A. Mikkola, "Review on the Absolute Nodal Coordinate Formulation for Large 
Deformation Analysis of Multibody Systems", J. Comput. Nonlinear Dyn., Vol. 8, 2013, pp. 1-12.

[35] W.-S. and Hyun-Woo Kim, "MBD applications in design”, Int. J. Non. Linear. Mech., Vol. 53, 2013, pp. 55-62.

[36] P. M. Laith K. Abbas, and Xiaoting Rui, "Panel flutter analysis of plate element based on the absolute nodal coordinate formulation", Multibody Syst Dyn, Vol. 27, 2012, pp. 135-152.

[37] J. Y. Q. Tian, Y. Zhang, and L. Chen, "Simulation of planar flexible multibody systems with clearance and lubricated revolute joints", Nonlinear Dyn., Vol. 60, 2010, pp. 489-511.

[38] C. Liu, Q. Tian, and H. Hu, "Dynamics and control of a spatial rigid-flexible multibody system with multiple cylindrical clearance joints", Mech. Mach. Theory, Vol. 52, 2012, pp. 106-129.

[39] V. D. Majda Cohodar, and Wolfgang Borutzky, "Comparison of different formulations of 2D beam elements based on Bond Graph technique", Simul. Model. Pract. Theory, Vol. 17, 2009, pp. 107-124.

[40] Q. Tian, Y. Zhang, L. Chen, and P. Flores, "Dynamics of spatial flexible multibody systems with clearance and lubricated spherical joints", Comput. Struct., Vol. 87, No. 1314, 2009, pp. 913-929.

[41] P. F. Qiang Tian, Yanlei Sun, Cheng Liu, and Haiyan $\mathrm{Hu}$, "ElastoHydroDynamic lubricated cylindrical joints for rigid-flexible multibody dynamics", Comput. Struct., Vol. 114-115, 2013, pp. 106-120.

[42] M. A. B. Ahmed A. Shabana, Florentina M. and Gantoi, "Integration of finite element and multibody system algorithms for the analysis of human body motion", Procedia IUTAM, Vol. 2, 2011, pp. 233-240.

[43] O. Dmitrochenko, "Finite elements using absolute nodal coordinates for large-deformation flexible multibody dynamics", J. Comput. Appl. Math., Vol. 215, 2008, pp. 368 - 377.

[44] G. R. Difeng Hong, and Jiali Tang, "Dynamic modeling of mass-flowing linear medium with large amplitude displacement and rotation", J. Fluids Struct., Vol. 27, 2011, pp. 1137-1148.

[45] H. R. J.L. Tang, G.X. Ren, and W.D. Zhu, "Dynamics of variable-length tethers with application to tethered satellite deployment", Commun Nonlinear Sci Numer Simulat, Vol. 16, 2011, pp. 3411-3424.

[46] G. Zhenxing Shen, QiangTian, and XiaoningLiu, "Thermally induced vibrations of flexible beams using Absolute Nodal Coordinate Formulation", Aerosp. Sci. Technol., Vol. 29, 2013, pp. 386-393.

[47] A. M. E.-A. and Ayman A. Nada, "Absolute nodal coordinate formulation of large-deformation piezoelectric laminated plates", Nonlinear Dyn, Vol. 67, 2012, pp. 2441-
2454 .

[48] Jingyu Yang, and Guoping Chen, "Robust Nominal Model-Based Sliding Mode Robust Control for Vibration of Flexible Rectangular Plate", Appl. Math, Vol. 7, No. 2L, 2013, pp. 671-678.

[49] S.-Q. Zhang, Y.-X. Li, and R. Schmidt, "Active shape and vibration control for piezoelectric bonded composite structures using various geometric nonlinearities", Compos. Struct., Vol. 122, 2015, pp. 239-249.

[50] M. P. C. Zhang S.Q., Li H.N. and Schmidt R., "Disturbance rejection control for vibration suppression of piezoelectric laminated thin-walled structures", J. Sound Vib., Vol. 333, 2014, pp. 1209-1223.

[51] Y. Luo, M. Xu, B. Yan, and X. Zhang, "PD control for vibration attenuation in Hoop truss structure based on a novel piezoelectric bending actuator", J. Sound Vib., Vol. 339, 2015, pp. 11-24.

[52] Sh. Z. and Rongbo He, "Independent modal variable structure fuzzy active vibration control of thin plates laminated with photostrictive actuators", Chinese J. Aeronaut., Vol. 26, No. 2, 2013, pp. 350-356.

[53] K. S. and Thomas Rittenschober, "Observer-based self sensing actuation of piezoelastic structures for robust vibration control", Automatica, Vol. 48, 2012, pp. 1123-1131.

[54] A. Reza, M. Mailah, I. Z. Mat, and O. Tokhi, "Selflearning active vibration control of a flexible plate structure with piezoelectric actuator", Simul. Model. Pract. Theory, Vol. 18, No. 5, 2010, pp. 516-532.

[55] I. Z. Mat Darus and M. O. Tokhi, "Soft computing adaptive active vibration control of flexible structures", Elsevier, 2005.

[56] C. Long-xiang, C. Guo-ping, and P. Ji, "Experimental study of delayed feedback control for a flexible plate", J. Sound Vib., Vol. 322, 2009, pp. 629-651.

[57] Z. Qiu, H. Wu, and D. Zhang, "Experimental researches on sliding mode active vibration control of flexible piezoelectric cantilever plate integrated gyroscope", Thin-Walled Struct., Vol. 47, No. 8, 2009, pp. 836-846.

[58] M. N. Ma, K. and Ghasemi-Nejhad, "Adaptive control of flexible active composite manipulators driven by piezoelectric patches and active struts with dead zones", Control Syst. Technol. IEEE Trans., Vol. 16, No. 5, 2008, pp. 897-907.

[59] R. Kumar, S. P. Singh, and H. N. Chandrawat, "MIMO adaptive vibration control of smart structures with quickly varying parameters: Neural networks vs classical control approach", J. Sound Vib., Vol. 307, 2007, pp. 639-661.

[60] L. W. Z. Lin J, "Experimental evaluation of a piezoelectric vibration absorber using a simplified fuzzy controller in a cantilever beam", J. Sound Vib., Vol. 296, 2006, 
pp. 567-582.

[61] J. Qiu, Z. and Ye, C. and Wei, “Experimental Study on Sliding Mode Variable Structure Vibration Control for Piezoelectric Cantilever Plate", in Intelligent Control and Automation, 2008. WCICA 2008. 7th World Congress on, 2008, pp. 1864-1868.

[62] L. Sun and W. Huo, "Robust adaptive relative position tracking and attitude synchronization for spacecraft rendezvous", Aerosp. Sci. Technol., Vol. 41, 2015, pp. 28-35.

[63] Z. C. Binglong Cong, and Xiangdong Liu, "Backstepping based adaptive sliding mode control for spacecraft attitude maneuvers", Aerosp. Sci. Technol., Vol. 30, 2013, pp. 1-7.

[64] S. N. S. Keum, and W. Lee, "L1 adaptive control of flexible spacecraft despite disturbances", Acta Astronaut. J., Vol. 80, 2012, pp. 24-35.

[65] B. Wu, D. Wang, and E. K. Poh, “Decentralized slidingmode control for spacecraft attitude synchronization under actuator failures", Acta Astronaut., Vol. 105, No. 1, 2014, pp. 333-343.

[66] X. S. TIAN Lin, “Attitude Control Considering Variable Input Saturation Limit for a Spacecraft Equipped with Flywheels", Chinese J. Aeronaut., Vol. 25, 2012, pp. 437-445.

[67] E. J. Findlay, A. de Ruite, J. R. Forbes, and J. Lee, "Magnetic Attitude Control of a Flexible Satellite, J. Guid. Dyn., Vol. 36, No. 5, 2013, pp. 1522-1526.

[68] M. N. A., Hanspete. S. Butcher, "Spacecraft Attitude Stabilization Using Nonlinear Delayed Multiactuator Control and Inverse Dynamics", J. Guid. Dyn., Vol. 36, No. 5, 2013, pp. 1440-1452.

[69] G. M. Chuanjiang Li, Kok Lay Teo, Bin Li, "A constrained optimal PID-like controller design for spacecraft attitude stabilization", Acta Astronaut. J., Vol. 74, 2012, pp. 131-140.

[70] Y. C. Yajie Ma, Bin Jiang Gang Tao, "Actuator failure compensation and attitude control for rigid satellite by adaptive control using quaternion feedbackv", J. Franklin Inst., Vol. 351, 2014, pp. 296-314.

[71] Santanu Das, Manoranjan Sinha, Arun K. Misra,
"Dynamic Neural Units for Adaptive Magnetic Attitude Control of Spacecraft", J. Guid. Dyn., Vol. 35, No. 4, 2012, pp. 1280-1291.

[72] Z. C. Binglong Cong, Xiangdong Liu, "Backstepping based adaptive sliding mode control for spacecraft attitude maneuvers", Aerosp. Sci. Technol., Vol. 30, 2013, pp. 1-7.

[73] Y. Z. Qinglei Hu, Bo Li, "Robust attitude control design for spacecraft under assigned velocity and control constraints", ISA Trans., Vol. 52, 2013, pp. 480-493.

[74] S.-Y. P. Mohammad Abdelrahman, "Spacecraft attitude control via a combined state-dependent Riccati equation and adaptive neuro-fuzzy approach", Aerosp. Sci. Technol., Vol. 26, 2013, pp. 16-28.

[75] Y. X. Kunfeng Lu, "Adaptive attitude tracking control for rigid spacecraft with finite-time convergence", Automatica, Vol. 49, 2013, pp. 3591-3599.

[76] M. G. and E. Bijami, "An efficient decentralized robust adaptive controller for a class of large-scale non-affine nonlinear systems with strong interactions", Neural Comput Applic, Vol. 24, 2014, pp. 463-471.

[77] Y.-S. H. H.-L. and Y.-X. Zhu, "Decentralized adaptive fuzzy control of large-scale nonaffine nonlinear systems by state and output feedback", Nonlinear Dyn, Vol. 69, 2012, pp. 1665-1677.

[78] X. Zhang and Y. Lin, "Adaptive output feedback control for a class of large-scale nonlinear time-delay systems", Automatica, Vol. 52, 2015, pp. 87-94.

[79] B.-C. Y. and Guang-Hong Zheng, "Decentralized sliding mode quantized feedback control for a class of uncertain large-scale systems with dead-zone input", Nonlinear Dyn, Vol. 71, 2013, pp. 417-427.

[80] D. J. H. Tengfei Liu, and Zhong-Ping Jiang, "Decentralized output-feedback control of large-scale nonlinear systems with sensor noise", Automatica, 2012, pp. 2560-2568.

[81] X. J. Shaocheng Tong, and Yongming Li, "Adaptive fuzzy decentralized dynamics surface control for nonlinear large-scale systems based on high-gain observer", Inf. Sci. (Ny)., Vol. 235, 2013, pp. 287-307. 